Suneela Vegunta, MD, FACP, NCMP

Division of Women's Health Internal Medicine,

Mayo Clinic, Scottsdale, AZ
Aakriti R. Carrubba, MD

Department of Medical and Surgical

Gynecology, Mayo Clinic, Jacksonville, FL
Megan N. Wasson, DO, FACOG

Department of Medical and Surgical Gynecology,

Mayo Clinic Hospital, Phoenix, AZ

\title{
Changing US trends in contraceptive choices
}

\section{ABSTRACT}

Long-acting reversible contraceptives (ie, intrauterine devices and the etonogestrel subdermal implant) have become increasingly popular methods of contraception because of their convenience and safety profile. At the same time, the use of depot medroxyprogesterone acetate, one of the most prescribed contraceptives in the United States since its approval in 1992, is on the wane. The history and pros and cons of these contraceptive methods are reviewed.

\section{KEY POINTS}

Depot medroxyprogesterone acetate (DMPA) must be administered by intramuscular injection (at a clinic) or subcutaneously (by the user) every 12 to 14 weeks.

Disadvantages to using DMPA include abnormal bleeding, weight gain, bone mineral density reduction, possible increased susceptibility to sexually transmitted infections, and ovulation delay after stopping use.

DMPA use has one of the highest discontinuation rates among all users of contraceptives.

Intrauterine devices (IUDs) (copper and levonorgestrel) are safe to use for nulliparity, pelvic inflammatory disease, heavy bleeding, and contraindications for estrogen therapy.

Contraindications for levonorgestrel IUDs include history of breast cancer, untreated cervical cancer, Müllerian anomalies, and gestational trophoblastic disease.

\footnotetext{
*Mayo Clinic does not endorse specific products or services included in this article.
} doi:10.3949/ccjm.88a.20110
$\mathrm{O}$ ver the past few decades, trends in the choice of contraceptive method have changed due to convenience, individual patient lifestyle, and adverse-effect profiles. Counseling patients on their best options can improve adherence and improve rates of unintended pregnancy.

This article examines the changing trends and reviews appropriate use of depot medroxyprogesterone acetate (17-acetoxy 6-methyl progestin; DMPA) and long-acting, reversible contraceptives (LARCs).

\section{DMPA: A LONG-ACTING, REVERSIBLE CONTRACEPTIVE}

DMPA is a long-acting, reversible progestational contraceptive without any estrogenic or androgenic activity. Although approved by the US Food and Drug Administration (FDA) in 1959 as a treatment for endometrial and renal cancers, it is now primarily used for contraception because of its ability to inhibit follicular maturation and ovulation.

\section{Cancer risk an early but disproved concern}

Subsequent to FDA approval for cancer therapy, DMPA was found to be a highly effective contraceptive at a 150-mg dose injected at 3-month intervals. ${ }^{1}$ However, the FDA denied approval as a contraceptive agent in 1969, 1978, and 1983 because of safety concerns, primarily increased risk of endometrial, breast, ovarian, and cervical cancers found in animal studies. ${ }^{2,3}$ However, the World Health Organization (WHO) later concluded no associated increased risk of breast, ovarian, or cervical cancers, and actually found substantially reduced endometrial cancer incidence and mortality. ${ }^{4}$ This led to approval of 
DMPA as a contraceptive in $1992,{ }^{4-6}$ after which DMPA quickly gained acceptance as one of few highly effective contraceptives at the time with a low per-dose cost.

\section{Subcutaneous route allows self-administration} In 2004, a subcutaneous form of DMPA was FDA-approved with a 30\% lower dose (104 mg every 3 months), offering an improved pharmacokinetic profile while providing more stability and sustained absorption because of low solubility. ${ }^{7}$ Although peak serum levels are lower, duration of action is the same as provided by the intramuscular injection. ${ }^{8}$ Subcutaneous DMPA can be administered in the thigh or abdomen every 12 to 14 weeks and was initially designed for self-administration in developing countries where patients have limited access to healthcare. ${ }^{9}$

\section{Noncontraceptive benefits}

DMPA has been recommended for female patients with certain medical conditions or preferences for the following reasons.

Bleeding reduction. DMPA can improve mean uterine and fibroid volume for patients with heavy menstrual bleeding from leiomyoma. ${ }^{10}$ In a study of female patients with diagnosed endometrial hyperplasia, DMPA was associated with regression in $92 \%$ of patients after 6 months of treatment. ${ }^{5}$ It should be considered for patients with endometrial hyperplasia who have contraindications to surgery range of contraceptive options and specific methods to fit their lifestyles and want to preserve fertility. ${ }^{11}$

Cancer prevention. DMPA is an effective chemopreventive agent for women at high risk of developing endometrial cancer (eg, patients with Lynch syndrome) ${ }^{6}$

Pelvic pain reduction. DMPA has success rates similar to other medical therapies for endometriosis (eg, danazol, combination contraceptives, gonadotropin-releasing hormone analogues) in managing deep dyspareunia and nonmenstrual pelvic pain after 1 year of use. ${ }^{12}$

\section{DMPA DRAWBACKS}

DMPA has substantial drawbacks that have contributed to a decline in use. ${ }^{13}$ It has the highest discontinuation rates among all contraceptives with side effects being the most common reason for stopping therapy. ${ }^{14}$ However, DMPA continues to be commonly used in sub-Saharan Africa. ${ }^{15}$
Adherence to therapy is another challenge for DMPA therapy as clinic visits are required 4 times a year for intramuscular injection. A Planned Parenthood study followed 5,178 female patients prescribed DMPA: $57 \%$ returned for the second injection, 36\% for the third injection, and only $23 \%$ continued therapy for 1 year. ${ }^{16}$ The mean 1 -year discontinuation rate has been reported to be $40 \%$ to $75 \% .{ }^{17}$

Subcutaneous DMPA is associated with more injection-site reactions such as skin dimpling from lipodystrophy, and it is more expensive than the intramuscular form. ${ }^{18}$

\section{Changes in menstrual bleeding}

Effects on menstrual bleeding are often cited as one reason patients discontinue using DMPA. ${ }^{9}$ Initially, progestin-only hormonal regimens can result in abnormal menstrual bleeding patterns; DMPA commonly causes spotting, irregular bleeding, and prolonged bleeding. ${ }^{4}$ With prolonged use, DMPA is associated with amenorrhea, which many patients consider to be a benefit. ${ }^{4,19}$ Reported rates are $52 \%$ to $64 \%$ at 12 months, and $71 \%$ at 24 months.

Combined hormonal contraceptives or estrogen supplementation may be used to manage bleeding in the short-term, but currently no effective long-term treatment methods have been identified. ${ }^{4}$ Decreasing the administration interval to 10 weeks can reduce irregular bleeding for patients who have bleeding close to their next scheduled injection time. Very heavy and bothersome bleeding patterns warrant additional evaluation.

\section{Ovulation delay}

The DMPA clearance rate is variable. In overweight or obese patients, DMPA may be detected for up to 9 months after a single injection. ${ }^{20}$ Generally, ovulation resumes within 14 weeks of DMPA discontinuation, although it may take up to 18 months. ${ }^{21}$ On average, an additional 5 to 8 months is required to conceive after DMPA use compared with nonhormonal methods of contraception. ${ }^{20}$

\section{Bone mineral density reduction}

In 2004, the FDA added a black-box warning to the DMPA label, cautioning that prolonged use could result in loss of bone mineral density (BMD). Patients were advised to use longterm DMPA therapy only if they were unable 
to use other contraception. ${ }^{22}$ Compared with IUD users, DMPA users have more BMD reductions after 12 months of use. ${ }^{23}$

Hypoestrogenism from DMPA administration increases bone resorption over bone formation, contributing to the drug's skeletal effects. ${ }^{24}$ Bone turnover markers, eg, alkaline phosphatase, increase within 12 months of DMPA use, suggesting increased bone resorption. In addition, glucocorticoid activity of DMPA decreases the proliferation of osteoblasts, leading to reduced bone formation. ${ }^{25}$

BMD loss appears to be more substantial in the initial 2 years of use, followed by a less intense nonlinear loss over the following years. ${ }^{23}$ In adolescent girls, BMD values return to normal after DMPA is discontinued, with no differences noted compared with nonhormone users. ${ }^{26}$ Perimenopausal patients who are vulnerable to a declining BMD may experience statistically significant bone loss with DMPA, increasing risk for developing osteoporosis. ${ }^{9}$ However, a large study supported the safety of DMPA for use for 2 years or less, with only a modestly elevated absolute fracture risk in users compared with nonusers (adjusted hazards ratio 1.15 [95\% confidence interval 1.01-1.31]). ${ }^{27}$

Use of DMPA beyond 2 years should not be absolutely contraindicated, as bone loss and fracture risk can return to baseline within 2 to 3 years after DMPA is discontinued, ${ }^{28}$ especially in female patients with intact ovarian function. Although controversial, this recommendation is supported by the WHO and American College of Obstetricians and Gynecologists, regardless of patient age. ${ }^{29}$ They recommend that providers discuss the black-box warning with patients, balancing the risks of using DMPA against the known health and social consequences associated with unintended pregnancy, particularly among adolescents. ${ }^{29}$

History of fracture is also not an absolute contraindication for DMPA use, and BMD monitoring is not recommended for current or previous DMPA users. However, it may be prudent to recommend lifestyle modifications, such as increasing physical activity, a diet rich in calcium, and vitamin D supplements.

Risk of sexually transmitted infections Evidence indicates that DMPA may increase susceptibility to chlamydia, gonorrhea, herpes simplex, and human immunodeficiency virus (HIV). ${ }^{4}$ Possible contributing causes are mucosal barrier disruption, inflammation, decreased humoral and cellular immune responses, and changes in the vaginal microbiome. ${ }^{30-33}$ Consequently, the WHO issued a caution that women using progestin-only injectable methods of contraception should be strongly advised to use barrier protection (ie, male or female condoms). ${ }^{4}$

The Evidence for Contraceptive Options and HIV Outcomes (ECHO) trial, conducted in sub-Saharan Africa, found that DMPA increased HIV transmission risk by $23 \%$ to $29 \%$ compared with the levonorgestrel IUD. ${ }^{34}$ The authors concluded that the differences were not substantial, and the WHO used the results of this study to relax medical eligibility criteria for DMPA use in female patients at high risk for HIV infection. However, the study had a number of limitations, including lack of a control group of nonusers, casting doubt about the value of the results. ${ }^{35}$ Further study is needed to provide clarity regarding HIV association.

\section{Weight gain}

Weight gain is a common concern for female patients starting contraceptive therapy. Most experts believe that DMPA use is more likely than other progestin contraceptives to lead to weight gain because of higher hormone levels and glucocorticoid activity.

Berenson et $\mathrm{al}^{36}$ found that 36 months of DMPA use was associated with an average increase in body weight of $5.1 \mathrm{~kg}$ and an increase in body fat, percent body fat, and central-to-peripheral fat ratio compared with use of a combined hormonal contraceptive or nonhormonal method. Another study found a mean weight change over 12 months of $2.2 \mathrm{~kg}$ for DMPA users vs $1.0 \mathrm{~kg}$ for levonorgestrel IUD users. ${ }^{37}$ In an unadjusted linear-regression model, DMPA use was associated with more weight gain than with use of a copper IUD. ${ }^{36}$

\section{RECOMMENDATIONS FOR USE}

DMPA is especially recommended as a contraceptive method for female patients with the following medical conditions and situations:

- Contraindications for estrogen-containing combined hormonal contraceptives, eg, migraine with aura (US Department of Health and Human Services Medical Eli-

\section{DMPA use has one of the highest discontinuation rates among all contraceptives}


gibility Criteria for Contraceptive Use [US $\mathrm{MEC}$ ] category 1 , ie, no restrictions), thrombogenetic variants (US MEC category 2, ie, advantages of using the method generally outweigh risks), and tobacco use in patients over age 35 (US MEC category 1). ${ }^{38}$

- DMPA does not appreciably affect blood pressure or increase risk of venous thromboembolism.

- Epilepsy: DMPA is associated with fewer antiepileptic drug interactions than combined hormonal contraceptives.

- Sickle cell disease: DMPA reduces the number of sickle cell crises. ${ }^{39}$

- DMPA can be used by female patients who have difficulty adhering to daily oral contraceptive regimens or have concerns about using implantable LARCs.

\section{IUDS: NONHORMONAL AND HORMONAL}

About 4.4 million women have an IUD in the United States, ${ }^{40}$ where it has been available since 1968 and has been credited with national declines in overall unintended and teenage pregnancies.

\section{Initial IUD had unacceptable risks}

IUDs were initially made in a variety of shapes Adverse effects, from different materials, including plastic and changes in menstrual bleeding, and adherence are often cited as reasons for discontinuing DMPA copper. ${ }^{41}$ In 1971, the Dalkon Shield gained popularity, with an estimated 2 million users. However, this device was associated with significant rates of pelvic inflammatory disease, about 7,900 IUD-related hospitalizations, and 5 deaths, which were related to the multifilament-braided design of the IUD strings. In 1974, the device was removed from the market, and the manufacturer was responsible for approximately $\$ 500$ million in compensatory and punitive damages, ultimately leading the company to file for bankruptcy. These events created controversy and distrust among patients seeking IUD contraceptive options.

\section{Copper IUDS, an improvement}

Alternate forms of IUDs have since been developed, including a copper-bearing version that debuted in the United States in 1988 (TCu380A or Paragard; CooperSurgical; Trumbull, CT). ${ }^{42,43}$ Copper ions disrupt sperm motility and viability, and also increase white blood cell and prostaglandin levels within the uterus to prevent fertilization.
Copper-bearing IUDs are associated with increased cramping and heavier bleeding than the levonorgestrel IUD, but they remain an option for patients wanting nonhormonal LARC (eg, breast cancer survivors). ${ }^{42}$

Copper-bearing IUDs are currently the only LARC option approved for emergency contraception and can be inserted up to 5 days after unprotected intercourse. Evidence is emerging that the levonorgestrel IUD may also be effective for this indication. ${ }^{43}$

\section{Levonorgestrel IUDs increasingly popular}

IUDs containing the progestin levonorgestrel first became available in 2001, with rates of use increasing from $1.8 \%$ in 2002 to $9.5 \%$ in 2012 $(P<.001)$, primarily in parous female patients who wanted to space additional pregnancies or who did not intend future pregnancies. ${ }^{44}$

Four levonorgestrel IUD options are now available: Mirena (levonorgestrel $52 \mathrm{mg}$, Skyla (levonorgestrel $13.5 \mathrm{mg}$, Kyleena (levonorgestrel $19.5 \mathrm{mg}$, and Liletta (levonorgestrel $52 \mathrm{mg}$ ). These hormone-containing IUDs are FDA-approved for use from 3 to 7 years, depending on the product.

A trained professional must insert an IUD. Procedural and postprocedural risks include expulsion $(5.8 \%)$ and uterine perforation $(0.1 \%) .45,46$

\section{Safe to use in many settings}

As the risk for pelvic inflammatory disease with IUDs is extremely low, no prior screening for sexually transmitted infections is necessary for asymptomatic and low-risk patients. IUDs may be offered to patients diagnosed with pelvic inflammatory disease as a contraceptive method. ${ }^{47,48}$ Removal of an IUD has no therapeutic benefit for patients being treated for pelvic inflammatory disease and is not recommended.

IUDs can be safely used in patients who are nulliparous (a practice supported by the American College of Obstetricians and Gynecologists and the American Academy of Pediatrics), have contraindications to estrogen therapy, want LARC without the need for regular medical visits, and have heavy menstrual bleeding.

\section{Contraindications}

Absolute contraindications for the levonorgestrel IUD include a history of breast cancer, Müllerian anomalies (involving an abnormal uter- 


\section{TABLE 1}

\section{Characteristics of commonly used contraceptive methods}

\begin{tabular}{|c|c|c|c|c|}
\hline Medical condition & DMPA & LNG-IUD & CHCs & Subdermal implant \\
\hline Unintended pregnancy rates & $\leq 1 \%{ }^{56}$ & $<1 \%$ & $9 \%$ & $<1 \%$ \\
\hline WHO effectiveness tier & 2 (highly effective) $^{57}$ & 1 (most effective) & 2 & 1 \\
\hline Drug interactions & Minimal & Minimal & Several ${ }^{58}$ & Minimal \\
\hline Influence on blood pressure & Minimal & Minimal & Can cause mild increase & Minimal$^{59}$ \\
\hline Venous thromboembolism & Minimal & Minimal & Slight increase in risk ${ }^{57}$ & Minimal $^{60}$ \\
\hline Weight gain & Yes $^{36}$ & Minimal & Minimal & Minimal59,61 \\
\hline Influence on bone density & Negative $^{23}$ & Minimal & Positive $^{62}$ & Minimal63 \\
\hline Endometrium & Antiproliferative ${ }^{4,6}$ & Antiproliferative $\mathrm{e}^{50}$ & Antiproliferative $e^{64}$ & Antiproliferative ${ }^{65}$ \\
\hline
\end{tabular}

CHCs = combined hormonal contraceptives; DMPA = depot medroxyprogesterone; LNG-IUD = levonorgestrel-releasing intrauterine device; WHO $=$ World Health Organization

ine cavity shape), untreated cervical cancer, and gestational trophoblastic disease with persistently elevated beta-human chorionic gonadotropin. ${ }^{49}$

The US MEC recommend against levonorgestrel IUDs in patients with endometrial cancer. However, recent evidence suggests that levonorgestrel IUDs can be used to treat patients with early-stage, low-risk endometrial cancer who want to preserve fertility or who are not good candidates for surgery. ${ }^{50}$

\section{Adverse effects}

The primary adverse effect of the 52-mg levonorgestrel IUD is unscheduled bleeding that may last up to 12 weeks after insertion; this should be discussed with patients during contraceptive counseling. ${ }^{46}$

Amenorrhea can also occur. A secondary analysis of the Contraceptive CHOICE Project found that it was reported by $4.9 \%$ of $1,80252-\mathrm{mg}$ levonorgestrel IUD users at 3 months, $14.8 \%$ at 6 months, and $15.4 \%$ at 12 months. ${ }^{51}$

Other levonorgestrel IUD dosages may have slightly different bleeding profiles.

Several studies have found that body fat mass and weight can increase with use of the levonorgestrel IUD. However, gains after 12 months of use were not significantly different from gains in copper IUD users in one study. ${ }^{52}$

\section{SUBDERMAL ETONOGESTREL IMPLANT}

The subdermal etonogestrel implant is another effective progestin-only LARC contraceptive option..$^{53}$ Inserted into the arm in an office procedure, it contains a single, radiopaque, extended-release rod that contains $68 \mathrm{mg}$ of etonogestrel (a metabolite of desogestrel) and lasts for 3 years. ${ }^{53}$

The most common adverse effects are irregular bleeding, headache, and implant-site hematoma..$^{53}$ No changes in BMD or substantial weight gain were reported after 12 months of use. ${ }^{54}$ Rates of discontinuation at 12 months for the subdermal implant are higher than for the levonorgestrel IUD or copper IUD, mostly due to menstrual cycle abnormalities. ${ }^{55}$

Comparisons of commonly used contraceptive methods are summarized in (Table 1). 4,6,23,36,50,56-65 More detailed recommendations can be found at websites for the US Centers for Disease Control and Prevention ${ }^{66}$ and the USMedical Eligibility Criteria for Contraceptive Use. ${ }^{67}$

\section{DISCLOSURES}

The authors report no relevant financial relationships which, in the context of their contributions, could be perceived as a potential conflict of interest. 


\section{REFERENCES}

1. Jain J, Jakimiuk AJ, Bode FR, Ross D, Kaunitz AM. Contraceptive efficacy and safety of DMPA-SC. Contraception 2004; 70(4):269-275. doi:10.1016/j.contraception.2004.06.011

2. American Health Consultants Inc. FDA board investigates DepoProvera safety. Contracept Technol Update 1983; 4(3):25-27. pmid:12266161

3. Wren LM. Depo Provera: still controversial. Int Health News 1988; 9(2):2-3, 8. pmid:12179873

4. The Faculty of Sexual and Reproductive Healthcare (FSRH) of the Royal College of Obstetricians and Gynaecologists. FSRH clinical guideline: progestogen-only injectable. https://www.fsrh.org/documents/cec-ceu-guidance-injectables-dec-2014/ Accessed November 16, 2021.

5. Nooh AM, Abdeldayem HM, Girbash EF, Arafa EM, Atwa K, AbdelRaouf SM. Depo-Provera versus norethisterone acetate in management of endometrial hyperplasia without atypia. Reprod Sci 2016; 23(4):448-454. doi:10.1177/1933719115623643

6. Lu KH, Loose DS, Yates MS, et al. Prospective multicenter randomized intermediate biomarker study of oral contraceptive versus Depo-Provera for prevention of endometrial cancer in women with Lynch syndrome. Cancer Prev Res (Phila) 2013; 6(8):774-781. doi:10.1158/1940-6207.CAPR-13-0020

7. Kaunitz AM, Darney PD, Ross D, Wolter KD, Speroff L. Subcutaneous DMPA vs. intramuscular DMPA: a 2-year randomized study of contraceptive efficacy and bone mineral density. Contraception 2009; 80(1):7-17. doi:10.1016/j.contraception.2009.02.005

8. Halpern V, Combes SL, Dorflinger U, Weiner DH, Archer DF. Pharmacokinetics of subcutaneous depot medroxyprogesterone acetate injected in the upper arm. Contraception 2014; 89(1):31-35. doi:10.1016/j.contraception.2013.07.002

9. Pharmacia \& Upjohn Company LLC, a Division of Pfizer Inc. DepoProvera-medroxyprogesterone acetate injection, suspension package insert. December 2020. New York, NY. http://labeling.pfizer.com/ ShowLabeling.aspx?id=522 Accessed November 16, 2021.

10. Venkatachalam S, Bagratee JS, Moodley J. Medical management of uterine fibroids with medroxyprogesterone acetate (Depo Provera): a pilot study. J Obstet Gynaecol 2004; 24(7):798-800. doi:10.1080/01443610400009543

11. Chandra V, Kim JJ, Benbrook DM, Dwivedi A, Rai R. Therapeutic options for management of endometrial hyperplasia. J Gynecol Oncol 2016; 27(1):e8. doi:10.3802/jgo.2016.27.e8

12. Vercellini P, De Giorgi O, Oldani S, Cortesi I, Panazza S, Crosignani PG. Depot medroxyprogesterone acetate versus an oral contraceptive combined with very-low-dose danazol for long-term treatment of pelvic pain associated with endometriosis. Am J Obstet Gynecol 1996; 175(2):396-401. doi:10.1016/s0002-9378(96)70152-7

13. ClinCalc.com. ClinCalc DrugStats Database. https://clincalc.com/DrugStats/Drugs/Medroxyprogesterone. Accessed November 16, 2021.

14. Paul C, Skegg DC, Williams S. Depot medroxyprogesterone acetate. Patterns of use and reasons for discontinuation. Contraception 1997; 56(4):209-214 doi:10.1016/s0010-7824(97)00140-6

15. Ross JA, Agwanda AT. Increased use of injectable contraception in sub-Saharan Africa. Afr J Reprod Health 2012; 16(4):68-80. pmid:23444545

16. Westfall JM, Main DS, Barnard L. Continuation rates among injectable contraceptive users. Fam Plann Perspect 1996; 28(6):275-277. pmid:8959418

17. Tinkle M, Reifsnider E, Ransom SP. Why women quit using Depo-Provera? AWHONN Lifelines 2001; 5(6):36-41. doi:10.1111/j.1552-6356.2001.tb01372.x

18. Shelton JD, Halpern V. Subcutaneous DMPA: a better lower dose approach. Contraception 2014; 89(5):341-343. doi:10.1016/j.contraception.2013.10.010

19. Arias RD, Jain JK, Brucker C, Ross D, Ray A. Changes in bleeding patterns with depot medroxyprogesterone acetate subcutaneous injection 104 mg. Contraception 2006; 74(3):234-238. doi:10.1016/j.contraception.2006.03.008
20. Schwallie PC, Assenzo JR. The effect of depo-medroxyprogesterone acetate on pituitary and ovarian function, and the return of fertility following its discontinuation: a review. Contraception 1974; 10(2):181-202. doi:10.1016/0010-7824(74)90073-0

21. Pardthaisong T. Return of fertility after use of the injectable contraceptive Depo Provera: up-dated data analysis. J Biosoc Sci 1984; 16(1):23-34. doi:10.1017/s0021932000014760

22. Omar H, Kives S. Depot medroxyprogesterone acetate (DMPA, Depo-Provera) in adolescents: what is next after the FDA black box warning? J Pediatr Adolesc Gynecol 2005; 18(3):183 doi:10.1016/j.jpag.2005.03.007

23. Quintino-Moro A, Zantut-Wittmann DE, Silva Dos Santos PN, Silva CA, Bahamondes L, Fernandes A. Changes in calcium metabolism and bone mineral density in new users of medroxyprogesterone acetate during the first year of use. Int J Gynaecol Obstet 2019; 147(3):319-325. doi:10.1002/ijgo.12958

24. Lara-Torre E, Edwards CP, Perlman S, Hertweck SP. Bone mineral density in adolescent females using depot medroxyprogesterone acetate. J Pediatr Adolesc Gynecol 2004; 17(1):17-21. doi:10.1016/j.jpag.2003.11.017

25. Shaarawy M, El-Mallah SY, Seoudi S, Hassan M, Mohsen IA. Effects of the long-term use of depot medroxyprogesterone acetate as hormonal contraceptive on bone mineral density and biochemical markers of bone remodeling. Contraception 2006; 74(4):297-302. doi:10.1016/j.contraception.2006.04.003

26. Scholes D, LaCroix AZ, Ichikawa LE, Barlow WE, Ott SM. Injectable hormone contraception and bone density: results from a prospective study. Epidemiology 2002; 13(5):581-587. doi:10.1097/00001648-200209000-00015

27. Raine-Bennett T, Chandra M, Armstrong MA, Alexeeff S, Lo JC. Depot medroxyprogesterone acetate, oral contraceptive, intrauterine device use, and fracture risk. Obstet Gynecol 2019; 134(3):581-589. doi:10.1097/AOG.0000000000003414

28. Rosenberg L, Zhang Y, Constant D, et al. Bone status after cessation of use of injectable progestin contraceptives. Contraception 2007; 76(6):425-431. doi:10.1016/j.contraception.2007.08.010

29. The American College of Obstetricians and Gynecologists Women's Health Care Physicians. Committee Opinion: depot medroxyprogesterone acetate and bone effects. Obstet Gynecol 2014; 123(6):13981402. doi:10.1097/01.AOG.0000450758.95422.c8

30. Kleynhans L, Du Plessis N, Black GF, et al. Medroxyprogesterone acetate alters Mycobacterium bovis BCG-induced cytokine production in peripheral blood mononuclear cells of contraceptive users. PLoS One 2011; 6(9):e24639. doi:10.1371/journal.pone.0024639

31. Louw-du Toit R, Hapgood JP, Africander D. Medroxyprogesterone acetate differentially regulates interleukin (IL)-12 and IL-10 in a human ectocervical epithelial cell line in a glucocorticoid receptor (GR)-dependent manner. J Biol Chem 2014; 289(45):31136-31149. doi:10.1074/jbc.M114.587311

32. Hapgood JP, Ray RM, Govender Y, Avenant C, Tomasicchio M. Differential glucocorticoid receptor-mediated effects on immunomodulatory gene expression by progestin contraceptives: implications for HIV-1 pathogenesis. Am J Reprod Immunol 2014; 71(6):505-512. doi:10.1111/aji.12214

33. Maritz MF, Ray RM, Bick AJ, et al. Medroxyprogesterone acetate, unlike norethisterone, increases HIV-1 replication in human peripheral blood mononuclear cells and an indicator cell line, via mechanisms involving the glucocorticoid receptor, increased CD4/ CD8 ratios and CCR5 levels. PLoS One 2018; 13(4):e0196043. doi:10.1371/journal.pone.0196043

34. Evidence for Contraceptive Options HIV Outcomes (ECHO) Trial Consortium. HIV incidence among women using intramuscular depot medroxyprogesterone acetate, a copper intrauterine device, or a levonorgestrel implant for contraception: a randomised, multicentre, open-label trial. Lancet 2019; 394(10195):303-313. doi:10.1016/S0140-6736(19)31288-7

35. Hapgood JP. Is the injectable contraceptive depo-medroxyprogesterone acetate (DMPA-IM) associated with an increased risk for HIV acquisition? The jury is still out. AIDS Res Hum Retroviruses 2020; 


\section{VEGUNTA AND COLLEAGUES}

36(5):357-366. doi:10.1089/AID.2019.0228 28

36. Berenson AB, Rahman M. Changes in weight, total fat, percent body fat, and central-to-peripheral fat ratio associated with injectable and oral contraceptive use. Am J Obstet Gynecol 2009; 200(3):329. e1-329.e3298. doi:10.1016/j.ajog.2008.12.052

37. Lopez LM, Edelman A, Chen M, Otterness C, Trussell J, Helmerhorst FM. Progestin-only contraceptives: effects on weight. Cochrane Database Syst Rev 2013; 7(7):CD008815. doi:10.1002/14651858.CD008815.pub3

38. US Centers for Disease Control and Prevention. https://www.cdc. gov/reproductivehealth/contraception/mmwr/mec/summary.html Accessed November 16, 2021.

39. Manchikanti A, Grimes DA, Lopez LM, Schulz KF. Steroid hormones for contraception in women with sickle cell disease. Cochrane Database Syst Rev 2007; (2):CD006261. doi:10.1002/14651858.CD006261.pub2

40. Hubacher D, Kavanaugh M. Historical record-setting trends in IUD use in the United States. Contraception 2018; 98(6):467-470. doi:10.1016/j.contraception.2018.05.016

41. Jacob's Institute of Women's Health. History of long-acting reversible contraception (LARC) in the United States. https://publichealth. gwu.edu/sites/default/files/downloads/projects/JIWH/LARC_History. pdf Accessed November 16, 2021.

42. Andersson K, Odlind V, Rybo G. Levonorgestrel-releasing and copper-releasing (Nova T) IUDs during five years of use: a randomized comparative trial. Contraception 1994; 49(1):56-72. doi:10.1016/0010-7824(94)90109-0

43. Turok DK, Gero A, Simmons RG, et al. Levonorgestrel vs copper intrauterine devices for emergency contraception. N Engl J Med 2021; 384(4):335-344. doi:10.1056/NEJMoa2022141

44. Mosher WD, Moreau C, Lantos $\mathbf{H}$. Trends and determinants of IUD use in the USA, 2002-2012. Hum Reprod 2016; 31(8):1696-1702. doi:10.1093/humrep/dew117

45. Heinemann K, Reed S, Moehner S, Minh TD. Comparative contraceptive effectiveness of levonorgestrel-releasing and copper intrauterine devices: the European Active Surveillance Study for Intrauterine Devices. Contraception 2015; 91(4):280-283. doi:10.1016/j.contraception.2015.01.011

46. McCarthy L. Levonorgestrel-releasing intrauterine system (mirena) for contraception. Am Fam Physician 2006; 73(10):1799-1802.

47. Esposito CP. Intrauterine devices in the context of gonococcal infection, chlamydial infection, and pelvic inflammatory disease: not mutually exclusive. J Midwifery Womens Health 2020; 65(4):562-566. doi:10.1111/jmwh.13120

48. Levin G, Dior UP, Gilad R, Benshushan A, Shushan A, Rottenstreich A. Pelvic inflammatory disease among users and non-users of an intrauterine device. J Obstet Gynaecol 2021; 41(1):118-123. doi:10.1080/01443615.2020.1719989

49. ESHRE Capri Workshop Group. Intrauterine devices and intrauterine systems. Hum Reprod Update 2008; 14(3):197-208. doi:10.1093/humupd/dmn003

50. Pal N, Broaddus RR, Urbauer DL, et al. Treatment of low-risk endometrial cancer and complex atypical hyperplasia with the levonorgestrel-releasing intrauterine device. Obstet Gynecol 2018; 131(1):109-116. doi:10.1097/AOG.0000000000002390

51. Mejia M, McNicholas C, Madden T, Peipert JF. Association of baseline bleeding pattern on amenorrhea with levonorgestrel intrauterine system use. Contraception 2016; 94(5):556-560. doi:10.1016/j.contraception.2016.06.013

52. Dal'Ava N, Bahamondes L, Bahamondes MV, de Oliveira Santos A Monteiro I. Body weight and composition in users of levonorgestrelreleasing intrauterine system. Contraception 2012; 86(4):350-353. doi:10.1016/j.contraception.2012.01.017
53. Clinical Review Report: etonogestrel extended-release subdermal implant (nexplanon): Merck Canada Inc. Ottawa (ON): Canadian Agency for Drugs and Technologies in Health; December 2020. https://www.ncbi.nlm.nih.gov/books/NBK567605/. Accessed November 16, 2021.

54. Romano ME, Braun-Courville DK. Assessing weight status in adolescent and young adult users of the etonogestrel contraceptive implant. J Pediatr Adolesc Gynecol 2019; 32(4):409-414. doi:10.1016/j.jpag.2019.03.008

55. Moray KV, Chaurasia H, Sachin O, Joshi B. A systematic review on clinical effectiveness, side-effect profile and meta-analysis on continuation rate of etonogestrel contraceptive implant. Reprod Health 2021; 18(1):4. doi:10.1186/s12978-020-01054-y

56. Curtis KM, Nguyen A, Reeves JA, Clark EA, Folger SG, Whiteman MK. Update to US selected practice recommendations for contraceptive use: self-administration of subcutaneous depot medroxyprogesterone. MMWR Morb Mortal Wkly Rep 2021; 70:739-743. doi:10.15585/mmwr.mm7020a2

57. Curtis KM, Jatlaoui TC, Tepper NK, et al. US selected practice recommendations for contraceptive use, 2016. MMWR Recomm Rep 2016; 65(4):1-66. doi:10.15585/mmwr.rr6504a1

58. Hillier K. Drug interaction with oral contraceptives. Fertil Contracept 1978; 2(1):5-8. pmid:12308946

59. Villas-Boas J, Vilodre LC, Malerba H, Pontremoli Salcedo M, Foresti Jiménez $\mathbf{M}$, El Beitune $\mathbf{P}$. Metabolic safety of the etonogestrel contraceptive implant in healthy women over a 3-year period. Eur J Obstet Gynecol Reprod Biol 2016; 202:51-54. doi:10.1016/j.ejogrb.2016.04.025

60. Sidney S, Cheetham TC, Connell FA, et al. Recent combined hormonal contraceptives (CHCs) and the risk of thromboembolism and other cardiovascular events in new users. Contraception 2013; 87(1):93-100. doi:10.1016/j.contraception.2012.09.015

61. Pam VC, Musa J, Mutihir JT, Karshima JA, Anyaka CU, Sagay AS. Body weight changes in women using implanon in Jos, Nigeria. Afr J Med Sci 2014; 43(Suppl):15-21. pmid:31217663

62. Liu SL, Lebrun CM. Effect of oral contraceptives and hormone replacement therapy on bone mineral density in premenopausal and perimenopausal women: a systematic review. Br J Sports Med 2006; 40(1):11-24. doi:10.1136/bjsm.2005.020065

63. Modesto W, Dal Ava N, Monteiro I, Bahamondes L. Body composition and bone mineral density in users of the etonogestrel-releasing contraceptive implant. Arch Gynecol Obstet 2015; 292(6):1387-1391. doi:10.1007/s00404-015-3784-0

64. Lüdicke F, Johannisson E, Helmerhorst FM, Campana A, Foidart J, Heithecker R. Effect of a combined oral contraceptive containing 3 $\mathrm{mg}$ of drospirenone and 30 microg of ethinyl estradiol on the human endometrium. Fertil Steril 2001; 76(1):102-107. doi:10.1016/s0015-0282(01)01834-9

65. Varma R, Mascarenhas L. Endometrial effects of etonogestrel (Implanon) contraceptive implant. Curr Opin Obstet Gynecol 2001; 13(3):335-341. doi:10.1097/00001703-200106000-00015

66. US Centers for Disease Control and Prevention. Summary of classifications for hormonal contraceptive methods and intrauterine devices. https://www.cdc.gov/reproductivehealth/contraception/ mmwr/mec/appendixk.html Accessed November 16, 2021.

67. US Centers for Disease Control and Prevention. https://www.cdc. gov/reproductivehealth/contraception/pdf/summary-chart-englishbw-508-tagged.pdf. Accessed November 17, 2021

Address: Suneela Vegunta, MD, Division of Women's Health Internal Medicine, Mayo Clinic, 13737 North 92nd Street, Scottsdale, AZ 85260; Vegunta.Suneela@mayo.edu 